\title{
Letters
}

Website: www.bmj.com

Email: letters@bmj.com

\section{Guidelines dismay disabled people unable to speak for themselves}

EDITOR-I am not just concerned about certain sections of the new BMA guidelines on withdrawing and withholding medical treatment ${ }^{1}-\mathrm{I}$ am afraid.

I have severe spina bifida and am a full time wheelchair user. I was appalled at the Law Lords' judgment in 1993 which allowed Tony Bland to have his food and fluids removed. Now I see that the new BMA guidelines would allow yet more disabled people unable to speak in their own defence to have nutrition and hydration withdrawn. ${ }^{1}$ There would no longer be even the minimal safeguard of a requirement that such cases be heard in court.

Despite the attempt of the chairman of the BMA's ethic committee to placate us by drawing a caricature of those who "believe passionately that life must be preserved at all costs," disabled people are quite smart enough to realise that providing food and fluids to patients who are not terminally ill is far from being heroic medical treatment. We know that withdrawing them is deliberate killing by neglect of patients who some doctors feel have lives not worth living.

A letter to the Lancet in 1991 noted that even then $30 \%$ of Dutch cancer patients

\footnotetext{
Advice to authors

We prefer to receive all responses electronically, sent either directly to our website or to the editorial office as email or on a disk. Processing your letter will be delayed unless it arrives in an electronic form.

We are now posting all direct submissions to our website within 24 hours of receipt and our intention is to post all other electronic submissions there as well. All responses will be eligible for publication in the paper journal.

Responses should be under 400 words and relate to articles published in the preceding month. They should include $\leqslant 5$ references, in the Vancouver style, including one to the BMJ article to which they relate. We welcome illustrations.

Please supply each author's current appointment and full address, and a phone or fax number or email address for the corresponding author. We ask authors to declare any competing interest. Please send a stamped addressed envelope if you would like to know whether your letter has been accepted or rejected.

Letters will be edited and may be shortened.

www.bmj.com

letters@bmj.com
}

were refusing to take prescription morphine or were taking lower doses than they had been prescribed, because they were afraid their doctors were trying to kill them. ${ }^{2}$ For people like me, who are taking strong painkillers, I foresee a similar state of fear if these guidelines are accepted. Who can we turn to, to feel safe, if we cannot trust doctors to act in our best interests both when we can communicate our wish to live and, more

People with disabilities like mine which are detectable prenatally know that BMA members willingly kill us before birth on the grounds solely of our having a "severe disability." We are also aware that some doctors already withdraw food and fluids from newborn babies with the same disabilities - a practice euphemistically called "allowing" them to die. We know that profoundly disabled people in the persistent vegetative state are dispatched by the same method, and now we read that other non-terminally ill disabled people are to be subjected to being pushed into death by their doctors. The trust that disabled people once had in doctors can only be restored when BMA members stop deliberately killing us. I urge your members to reject these guidelines.

Alison Davis patient

35 Stileham Bank, Milborne St Andrew, Blandford Forum, Dorset DT11 0LE

1 British Medical Association. Withholding and withdrawing life-prolonging medical treatment: guidance for decision making. London: BMJ Books, 1999

2 Zylicz Z. Euthanasia. Lancet 1991;338:1150.

\section{Measuring outcomes in economic evaluations}

\section{This economics note is misleading}

EDITOR-The series of occasional notes on economics has undoubtedly helped clinicians to understand the key concepts and jargon used by economists. The note discussing the use of outcome measures in economic evaluation is, however, misleading. ${ }^{1}$

Firstly, condition specific outcome measures and generic quality of life scales should not, in general, be used in cost effectiveness analysis. ${ }^{2}$ The primary reason for this is that such scales do not have the requisite interval properties. The scores produced by the short form-36 questionnaire (SF-36), for crucially, when we cannot? example, are little more than transformed ordinal rankings.

Even if interval properties can be shown, the use of generic quality of life scales in cost effectiveness analysis is severely restricted by their production of a set of scores reflecting different domains of health. For example, if the SF-36 is used in an evaluation, it can produce conflicting cost effectiveness ratios with respect to its various dimension scores. ${ }^{2}$ It is best to restrict the set of outcome measures appropriate for cost effectiveness analysis to those measured in natural units. ${ }^{3}$ Following such an approach would limit the direct use of health scales to cost consequences analyses-that is, the presentation of cost and outcome data in a disaggregated format. ${ }^{4}$

Secondly, the paper restricts its commentary on cost utility analysis to the use of utility based quality of life scales as the measure of outcome. Use of such scales is increasing and will become the dominant form of utility measurement in clinical research. However, health state valuation techniques, such as the standard gamble and the time trade off, ${ }^{5}$ may be used to produce study specific utility values. Such techniques are also the basis for the values awarded by the utility scales.

Thirdly, the economics note should point out that the use of willingness to pay and conjoint analysis is developmental, and their use in cost benefit analysis (as opposed to simple investigation of the patient's preferences) is extremely rare. It should also be noted that both of these approaches are valuation techniques, as opposed to outcome measures. As such, they can be used only if the effects or characteristics of the interventions have already been measured.

We recognise that this series of short articles must simplify important issues to remain concise. As it stands, however, this economics note is likely to mislead readers regarding good practice and commonly accepted practice.

Simon Dixon lecturer

Colin Green research fellow

Sheffield Health Economics Group, School of Health and Related Research, University of Sheffield, Sheffield S1 4DA

1 Torgerson D, Raftery J. Measuring outcomes in economi evaluations. BMJ 1999;318:1413. (22 May.)

2 Brazier J, Dixon S. The use of condition specific outcome measures in economic appraisal. Health Econ 1995;4:255-

3 Palmer S, Byford S, Raftery J. Types of economic evaluation. BMJ 1999;318:1349. (15 May.)

4 Drummond MF. Economic analysis alonoside controlled trials: an introduction for clinical researchers. Leeds: Department of Health, 1994.

5 Froberg DG, Kane RL. Methodology for measuring health-state preferences-II: Scaling methods. J Epidemiol 1989:42:459-71. 


\section{Author's reply}

Editor-We disagree with Dixon and Green that our note is misleading about what is good practice and commonly accepted practice. We did not suggest that cost effectiveness ratios should be constructed using non-utility measures such as the short form-36 questionnaire (SF-36). Rather, we argued for the inclusion of utility based measures as well as other quality of life measures. But utility measures are relatively insensitive to important changes in both clinical quality of life and quality of life relevant to the patient, which is one reason why we are reluctant to recommend that they be used alone.

In a recent evaluation of an intervention for low back pain the experimental group of patients had on average a $2 \%$ increase in utility (as measured by the EuroQol (European quality of life instrument)), but this was not significant $(\mathrm{P}=0.47) .{ }^{1}$ Both of the two back-pain condition specific measures, however, showed a significant improvement in back pain $(\mathrm{P}=0.01$ and $\mathrm{P}=0.02)$, which suggests that the non-significant utility benefit as measured by the EuroQol was true. Had these condition specific measures shown no improvement there would be doubt as to whether there was any utility benefit of this intervention. Thus, as we suggested in our note, the use of non-utility outcome measures can aid interpretation of a trial's results and compensate for poor sensitivity of utility measures. We think that it is good practice to include both a utility based measure of outcome and non-utility measures of quality of life.

Dixon and Green's second point regarding health state valuation techniques is valid, but we restricted ourselves to talking about a utility measure; given the mainly clinical readership of the $B M J$, this is more likely to be familiar to them. We also agree with the authors about the relative rarity of willingness to pay and conjoint analysis; as the use of these techniques in health economics has increased in recent years, however, we thought that they ought to be mentioned.

David J Torgerson senior research fellow

University of York, York YO23 5DD

1 Moffett JK, Torgerson DJ, Bell-Syer S, Jackson D, LlewlynPhillips H, Farrin A, et al. Randomised controlled trial of exercise for low back pain: clinical outcomes, costs, and preferences. BMJ 1999;319:279-83. (31 July.)

\section{Treatment of oral cancer}

\section{Radiotherapy may be as effective as surgery}

EDITOR-In her review article on oral cancer, ${ }^{1}$ Zakrzewska takes a strongly surgical view of its treatment and does not give a balanced view of the benefits and toxicities of surgery and radiotherapy. I take issue with her statements that "treatment for oral cancer is principally surgical," that "radiotherapy and chemotherapy are often used for adjuvant and adjunctive therapy," and that "radiotherapy is rarely used as a primary treatment." It is fairer to say that surgery and radiotherapy are the only curative treatments for oral cancer. Adjuvant chemotherapy with platinum containing regimens may improve local control but at the expense of enhanced toxicity.

Interstitial radiotherapy alone or in combination with external beam is an important component in curative treatment of squamous carcinomas of the floor of the mouth and tongue. ${ }^{23}$ In a series of 166 patients from France treated by iridium-192 implantation alone, the five year local control rate for stage T1-T2 node negative cancers of the anterior two thirds of the tongue was $87 \%$, with cause specific survival of $90 \%$ for $\mathrm{T} 1$ and $71 \%$ for $\mathrm{T} 2$ cancers respectively. ${ }^{3}$

Zakrzewska states that ablative surgery "is used to improve healing and restore function and improve the patient's quality of life." She does not mention the mutilating effects of surgery for oral cancer but cites oral mucositis and osteoradionecrosis as complications of radiotherapy. Radiotherapy's main advantage over surgery is that it preserves normal anatomy and function, an important determinant of quality of life. A study comparing radiotherapy with surgery at the base of the tongue concluded that radiotherapy resulted in fewer side effects, irrespective of stage, without adversely affecting prognosis. ${ }^{4}$ Zakrzewska rightly commends the importance of quality of life assessments. However, the real impact of the different but substantial toxicities of surgery and radiotherapy for oral cancer are often most eloquently described in patients' own words. ${ }^{5}$ Patients need to be briefed in detail of the trade off between local control and toxicity from surgery, radiotherapy, and chemotherapy when coming to an informed decision about treatment for oral cancer.

Ian Kunkler consultant in clinical oncology Western General Hospitals NHS Trust, Crewe Road, Edinburgh EH4 2XU

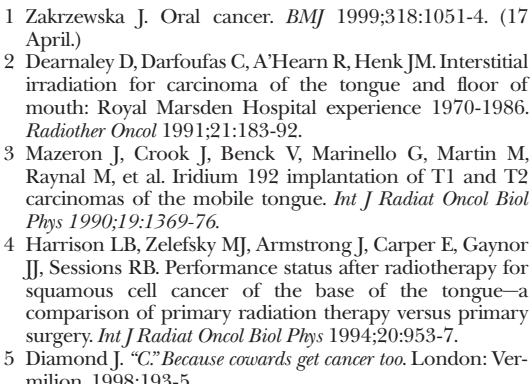
milion, 1998:193-5.

\section{Biopsy under local anaesthetic is inadequate}

EDITOR-Zakrzewska's article on oral cancer $^{1}$ does not mention the important risk of patients presenting with synchronous primary tumours of the upper aerodigestive tract. $^{2}$ She states that a biopsy under local anaesthetic is the most important investigation in diagnosing oral cancer. We believe that biopsy under local anaesthetic has little or no role in the investigation of these patients. Superficial biopsy specimens taken under local anaesthetic may indeed confirm the diagnosis, but assessment is incomplete unless deeper specimens are obtained to confirm the degree of invasion. These can be difficult to obtain under local anaesthesia. More importantly, general anaesthesia also allows formal pan-endoscopy to assess the whole of the upper aerodigestive tract and exclude "silent" synchronous tumours.

Finally, the author suggests that all patients with suspected oral cancer should be referred to an oral physician or an oral and maxillofacial surgeon. It is our view, and that of our specialist associations, ${ }^{3}$ that such cases should be referred to multidisciplinary head and neck oncology clinics. Indeed, this philosophy is supported by the recommendations of the Calman-Hine report.

G Cox clinical coordinator

C. Alcock lead clinician

R Corbridge specialist registrar (ear, nose, and throat) Oxford Centre for Head and Neck Oncology,

Radcliffe Infirmary NHS Trust, Oxford OX2 $6 \mathrm{HE}$

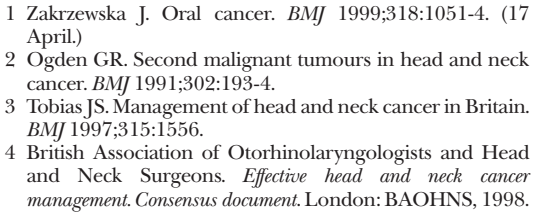

1 Zakrzewska J. Oral cancer. BMJ 1999;318:1051-4. (17 April.)

2 Ogden GR. Second malignant tumours in head and neck cancer. BMJ 1991;302:193-4.

3 Tobias JS. Management of head and neck cancer in Britain. BMJ 1997;315:1556.

British Association of Otorhinolaryngologists and Head British Association of Otorhinolaryngologists and Head
and Neck Surgeons. Effective head and neck cancer and Neck Surgeons. Effective head and neck cancer
management. Consensus document. London: BAOHNS, 1998.

\section{Concerns about privacy in research may be exaggerated}

EDITOR-The risk of misusing electronic patient records has been pointed out, ${ }^{1}$ and there is also justified professional concern about privacy in medical research. We have enrolled 1.14 million people in a register based cancer study in the seven counties of Sweden that were most contaminated after the Chernobyl accident.

According to the permit from the responsible authority (the Data Inspection Board), we had to inform the public in these counties because of the principle of informed consent. This presented practical problems, so an advertisement was published in the two largest national newspapers, which together have a daily circulation of 538000 (the Swedish population is 8.8 million). In the advertisement we stated that anyone could contact us to check whether they were included in the study and what data were registered. This advertising was picked up by journalists, with interviews in both national and local television stations as well as radio stations.

Seventeen local newspapers in the seven counties, with a total circulation of 392300 copies a day, published articles about the study. After this broad media attention for a study that had not even started we feared a large response from the public, especially people who did not want to take part. Interestingly, however, the few responses we got were from people who wanted to join the study. Only one person wanted to use his legal rights to obtain the information in his record, but he did not want to quit the study. 
As newspapers, radio, and television are widespread in Sweden, most people in the seven counties studied are likely to have been informed about the study. The reason why we met no objections might be that the population believes the study to be important. It was obvious that they did not consider that the study was such a violation of privacy as is often implied by the scientific community or legislators.

Our experiences might be unusual, but they might also be applicable to other environmental (or even occupational) cohort studies, especially if based on registers. Interestingly, to our knowledge, not a single case of individual harm has occurred worldwide because of inclusion in an epidemiological study. Our experiences provide another argument when similar study proposals are considered by ethics committees or authorities that want to restrict the use of registers for epidemiological purposes.

Martin Tondel doctor

Martin.Tondel@lio.se

Olav Axelson professor

Division of Occupational and Environmental

Medicine, Department of Health and Environment,

Faculty of Health Sciences, Linköping University,

58185 Linköping, Sweden

1 Denley I, Smith SW. Privacy in clinical information systems in secondary care. BMJ 1999;318:1328-31. (15 May)

\section{Minimising the impact of visual impairment}

From October this will have to be done to conform to the law

EDITOR-Margrain's editorial on minimising the impact of visual impairment is firmly based on the medical model of disability, which locates disability in individuals. ${ }^{1}$ Disabled people have developed the social model as an accurate description of their life experience, and the World Health Organisation is revising its definition of disability to take this into account. ${ }^{2}$ The social model locates disability in society; therefore it is society that causes "much individual suffering and economic hardship," not visual impairment.

The editorial refers to the percentage of visually impaired people who could read normal print before and after the provision of a low vision aid and some training. But if everyone who produced information in print realised that the size of the print (or the use of print) can exclude people from gaining access to the information all information might be fully accessible.

Under the terms of the Disability Discrimination Act 1995, from October 1999 those who offer goods or services to the public are required to take reasonable steps to ensure that disabled people can make use of their services. A code of practice makes specific reference to the provision of documents in larger or clear print, Moon, or Braille; information on computer diskette; information on audiotape; and telephone services to supplement other information. ${ }^{3}$

For the health sector this means, for example, that hospital and primary care information must be available in formats accessible to everyone. The data given in the editorial about the number of people who are visually impaired indicates how many people potentially face discrimination if providers of goods and services do not produce information that is fully accessible.

The Royal National Institute for the Blind recently reported a survey of health authorities and NHS trusts in Great Britain. Of the 326 trusts that responded to a questionnaire, $35 \%$ offered general information for patients in large print but only $4 \%$ could provide test results in that format The Royal College of Physicians' charter for disabled people using hospitals states that "every disabled patient, visitor, or hospital employee has the right to relevant and accessible information, especially about the hospital's provision for disabled people."

The principle of ensuring that disabled people are not marginalised can be applied not only to the provision of information but also to other aspects of minimising the impact of an impairment. From October this will no longer be merely about good practice and equity but about conforming to the law.

Joyce M Carter consultant in public health medicine Liverpool Health Authority, Liverpool L3 6AL Joyce.Carter@liverpool-ha.nwest.nhs.uk

Natalie Markham disability equality officer Liverpool City Council and Liverpool Health Authority, Liverpool L3 2AW

1 Margrain TM. Minimising the impact of visual impairment. BMJ 1999;318:1504. (5 June.)

Oliver M. Theories of disability in health practice an research. BMJ 1998;317:1446-9.

3 Disability Discrimination Act 1995: code of practice. Rights of access. Goods, facilities, services and premises. London: Department for Education and Employment, 1999.

4 Royal National Institute for the Blind. Ill informed-the provision of accessible health and medical information. London: RNIB, 1998. (Campaign report 7.)

5 Royal College of Physicians. Disabled people usin hospitals-a charter and guidelines. London: RCP, 1998.

\section{Training in use of low vision aids is important}

EDITOR-Margrain discussed how many people with poor vision are not benefiting from low vision aids, but he underemphasised the importance of training in their use. ${ }^{1}$ Without training, many aids are likely to be underused and the reading ability in clinics may not be maintained at home.

Traditionally, hospital clinics for low vision have been run by optometrists on a comparatively infrequent basis. The emphasis has been on dispensing optical aids, including more complex spectacle mounted devices, with comparatively little time being available for training. In a recent postal survey I found that half the clinics in north west England are run solely by visiting optometrists on a monthly basis; in an audit of one such clinic I found that aids costing a third of the annual budget of $£ 11000$ had never been used and that the proportion of patients who were able to read newsprint rose from $16 \%$ to only $23 \%$. Humphrey and
Thompson showed that only 23\% of patients had found their aids useful at home, ${ }^{2}$ and Mcllwaine et al reported that $33 \%$ had never used the aids provided. ${ }^{3}$

In contrast, detailed analysis of a more integrated approach in Scandinavia found that $80 \%$ of patients with macular degeneration related to age were still able to read newsprint five years after being trained by a special teacher over several hours in how to use low vision aids. ${ }^{4}$ Less intensive training provided by orthoptists in Torbay (an average of 84 minutes per patient) produced good functional results and significantly greater patient satisfaction than in the study of Mcllwaine et al. ${ }^{5}$ This training seemed to be cost effective because of its emphasis on simpler and cheaper aids which offset staffing costs.

Further study is warranted to establish the best form of integrated, cost effective low vision service and how it might replace the comparatively ineffective and wasteful service still provided in many hospitals.

Wayne Birchall senior house officer

Royal Eye Hospital, Manchester M13 9WH moira.pagan@virgin.net

1 Margrain TH. Minimising the impact of visual impairment BMJ 1999;318:1504. (5 June.)

2 Humphrey RC, Thompson GM. Low vision aidsevaluation in a general eye department. Trans Ophthalmo Soc UK 1986;105:296-303.

3 Mcllwaine GG, Bell JA, Dutton GN. Low vision aids-is our service cost effective? Eye 1991;5:607-11

4 Nillson UL, Nillson SEG. Rehabilitation of the visually handicapped with advanced macular degeneration. Doc Ophthalmol 1986;62:345-67.

5 Shuttleworth GN, Dunlop A, Collins JK, James CRH. How effective is an integrated approach to low vision rehabilitation? Two year follow-up results from South Devon. $B r J$ Ophthalmol 1995;79:719-23.

\section{Many visual aids to help people with diabetes are no longer available}

Editor-One thing that Margrain does not discuss in his editorial on minimising the impact of visual impairment ${ }^{1}$ is the difficulty that people with diabetes and visual impairment experience when their diabetes requires insulin treatment or home glucose monitoring. There has been a gradual loss of visual aids to help people with diabetes to inject or monitor themselves. In the past various devices were available: speaking meters, fixed dose syringes, click count syringes, syringe carriers, magnifying lenses, and dose guide cards, as well as cartridge filled pens and prefilled pens. Many of these are no longer available, and we fear that recent government proposals on insulin pens and pen needles may limit prefilled pens as well.

Diabetes is often associated with visual impairment. By increasing visual aids rather than decreasing them, specific effort should be made to encourage diabetic people to look after themselves.

A C Burden consultant physician

Mary L Burden diabetes specialist nurse, research and development

Leanne Hayward medical student

Directorate of Medicine, Leicester General Hospital NHS Trust, Leicester LE5 4PW

1 Margrain TH. Minimising the impact of visual impairment. BMJ 1999;318:1504. (5 June.) 


\section{Antithrombotic treatment for atrial fibrillation}

\section{Patients must be told full details of risks of treatment}

EDITOR-The findings of Howitt and Armstrong's study of antithrombotic treatment for atrial fibrillation in general practice-in particular that patients were unwilling to take warfarin-have uncertain clinical relevance. ${ }^{1}$ They are in contrast to those of Sudlow et al, who reported that most elderly patients with atrial fibrillation would accept treatment to prevent stroke. ${ }^{2}$

The precise information provided to patients is critically important in influencing their beliefs. Lack of detail on the information provided about the drugs mars Howitt and Anderson's study. The authors emphasised the value of a patient centred approach in determining antithrombotic treatment in chronic atrial fibrillation and presented to patients, in pictorial fashion, the benefits (derived from clinical trials) of warfarin and aspirin. An equally important methodological issue, however, is the presentation of the risks of the treatment.

The methods section states only that "detailed information about aspirin and warfarin treatment was given." What exactly does this mean? If the material consisted of the typical prescribing information for warfarin or even the equally daunting consumer drug information developed by pharmaceutical companies, it is not surprising that many patients were frightened off treatment.

Adopting a patient centred approach to therapeutic decision making requires that the potential risks of the treatment are presented in as patient friendly a manner as the possible benefits.

Gregory Peterson associate professor

School of Pharmacy, Faculty of Health Science, University of Tasmania, GPO Box 252-26, Hobart TAS 7001, Australia

G.Peterson@utas.edu.au

1 Howitt A, Armstrong D. Implementing evidence based medicine in general practice: audit and qualitative study of antithrombotic treatment for atrial fibrillation. BMJ antithrombotic treatment
1999;318:1324-7. (15 Mav.)

2 Sudlow M, Thomson R, Kenny RA, Rodgers H. A commuSudlow M, Thomson R, Kenny RA, Rodgers H. A commu-
nity survey of patients with atrial fibrillation: associated nity survey of patients with atrial fibrillation: associated
disabilities and treatment preferences. $\mathrm{Br} J$ Gen Pract disabilities and

\section{Authors' reply}

EDITOR-The interventions in the two studies (ours and that of Sudlow et al) were fundamentally different and cannot be directly compared. Sudlow et al did not give patients advice about anticoagulant treatment explicitly but asked their views on a "therapy to prevent a stroke even if it involved frequent blood tests." In our study, patients were given explicit information about warfarin and aspirin, and $93 \%$ of patients were taking one of the treatments at the end of the study.

Other studies have addressed the uptake of treatment with warfarin alone, without considering aspirin. ${ }^{12}$ In reality, patients have a choice between an effective but potentially hazardous treatment for which the evidence base is strong and another less effective but safer treatment for which trial results are less conclusive. Perhaps the fact that we gave patients this option contributed to the low uptake of warfarin in our study.

Alistair Howitt principal in general practice Warders Medical Centre, Tonbridge, Kent TN9 1LA ajhowitt@warders.co.uk

David Armstrong reader in sociology as applied to medicine

Department of General Practice, Guy's, King's And St Thomas's School of Medicine, London SE11 6SP

1 Caro JJ, Groome PA, Flegel KM. Atrial fibrillation and anticoagulants: from randomised trials to practice. Lance 1993:341:1381-4.

2 Man-Son-Hing M, Laupacis A, O'Connor A, Wells C, Lemelin J, Wood W, et al. Warfarin for atrial fibrillation Lemelin J, Wood W, et al. Warfarin for atrial fibrillation.
The patient's perspective. Arch Intern Med The patient's

* Details of the information given to patients are available on the $B M$ Js website, www.bmj.com.

\section{Rationing health care in New Zealand}

\section{Explicit rationing needs more debate}

EDITOR-In their article on rationing health care in New Zealand Feek et al call for clinicians to accept the link between clinical decision making and resource allocation. Clinicians in New Zealand are very aware of this link but ask that politicians accept the complexity and uncertainty inherent in clinical decisions, the changing knowledge base of medicine, and the heterogeneity of patients.

Guidelines to determine access to care have now been introduced for several services (predominantly surgical) in New Zealand. Making these guidelines explicit raises several concerns. Explicit evidence based guidelines may not best serve the interests of patients and society. Although it is optimal to attempt to practise using the best available evidence, this approach has limitations. Evidence is limited; randomised controlled trials cannot be done in all cases (because of ethical and cost constraints) and produce problems in generalising from highly selected subjects to patients seen in everyday practice. Guidelines that define an access cut off point tend to be rigid rather than guiding and, in the light of concerns about the validity of the scoring process itself, are inequitable. They are slow to change as the evidence changes, cannot accommodate complexity, and may threaten social cohesion, ${ }^{2}$ leading to anxiety and loss of confidence in the health system as a whole.

I am not advocating that we return to the era when all allocative decisions were hidden from view, but I question the assertion that explicitness trumps all other concerns. Policy makers in New Zealand should pause and debate its relative merits more openly. Although the authors state that the public has accepted the need for explicit rationing, a fairer description would be resignation. There has been a paucity of debate of the practical and ethical dimensions. The following quote from Feek demonstrates how limited the debate has been: "The ethical paradigm does not provide a useful framework for evaluation of any rationing decision."

Any allocative decision that involves public funds and the denial of services is concerned with the distributive theories of justice. Ethical issues are definitely involved with the rationing of renal dialysis on the basis of age, ${ }^{4}$ and, furthermore, the renal dialysis example focuses the debate on so called tragic choices. ${ }^{5}$ This risks distorting priorities away from complex chronic conditions, which, after all, consume more of the health dollar.

Mary Seddon Harkness fellow in health care policy Department of Health Care Policy, Harvard Medical School, Boston, MA 02115, USA seddon@hcp.med.harvard.edu

1 Feek CM, McKean W, Henneveld L, Barrow G, Edgar W, Paterson RJ. Experience with rationing health care in New Zealand. BMJ 1999;318:1346-8. (15 May.)

2 Mechanic D. Professional judgement and the rationing of medical care. University of Pennsyluania Law Review 1992;140(5):1713-54.

3 Feek C, Hefford B, Morris F, Adam G, Edwards J. Notes from meeting with Health Legal re medico-legal matters and the booking systems policy. In: Evans D, Price N. The ethical dimensions of the national waiting time project: a report prepared for the health funding authority. Wellington: Ministry prepared for the he

4 Kjellstrand CM. High-technology medicine and the old: the dialysis example. J Intern Med 1996;239:195-210.

Klein R, Day P, Redmayne S. Managing scarcity. Priority setting and rationing in the National Health Service. Buckingham: Open University Press, 1996

\section{Author's reply}

EDitor-Seddon seems to agree that there is complexity and uncertainty in clinical decision making. Where she appears to differ from us is in the degree to which these decisions should be open to public scrutiny.

Her claim that public acceptance of rationing would be better described as resignation seems to be simply that-her claim. I feel we accurately portrayed the public mood by reflecting media coverage both in our paper and in our presentation at the second international conference on priorities in health care in London in October 1998.

Her claim of a "paucity of debate of the practical and ethical dimensions" of rationing ignores the considerable ethical debate around the provision of core services in New Zealand which began in 1993 and continues today.

We agree that ethical issues do contribute to this debate but differ on how it should happen. It should not be at the level of regional ethics committees-linked with most major hospitals in New Zealand. I quote from a letter from the Associate Minister of Health to the chairpersons of regional ethics committees in September 1996:

Virtually every resource allocation and access decision made about health and disability services has an ethical dimension because these decisions impact on patients ... It is the responsibility of Government, regional health authorities, Crown Health Enterprises, other 
service provider managers, and clinicians to address these ethical issues. Because other health sector organisations have these responsibilities, the roles of the regional and national committees are limited.

Seddon is misguided about the development of guidelines in New Zealand. The guidelines for renal failure are boundary guidelines and reflect current clinical decision making processes. They are not rigid but guide clinicians in an envelope of resource allocation. They are based on a wide range of clinical factors. The guidelines are used as a tool to communicate how clinical decisions are made to patients, the public, and politicians alike. Publicising this information will help to improve public confidence and social cohesion, providing that the process is seen to be open and fair.

Colin Feek chief medical adviser

Ministry of Health, PO Box 503, Wellington, New Zealand

Colin_Feek@moh.govt.nz

\section{Greenwich asthma study}

EDITOR-Premaratne et al's study highlights the difficulties encountered in implementing the British Thoracic Society's guidelines for asthma in Greenwich, ${ }^{1}$ an inner city area which has a high incidence of urban deprivation with all its attendant problems known to have an impact on asthma and quality of life.

When this study took place there was an explosion of asthma education for practice nurses, and it would have been useful to compare asthma knowledge and services within the control and intervention groups. The authors acknowledge that an initiative by the area's family health services authority, targeting the underuse of inhaled steroids in general practice, affected general practitioners' prescribing and that an unusually high turnover of practice nurses within the intervention group had an impact on the service provided. In view of these influences it seems unlikely that the control group was untainted, and the study results become difficult to interpret.

Only $26 \%$ of registered asthmatic patients were seen by nurses in the intervention practices. The project therefore failed to target a large number of asthmatic patients $(74 \%)$. We do not know if these patients were being seen by general practitioners, failed to keep appointments, had asthma that was too mild to be a problem, or had more severe or uncontrolled asthma and were more likely to be admitted to hospital or attend accident and emergency departments. Conclusions have been drawn therefore from a relatively small sample of the total number of asthmatic patients available, a group the authors say had relatively mild disease compared with patients in other studies.

Although the intervention was integrated across both primary and secondary care, there is no evidence to show that it was applied anywhere but in the primary sector. There is no mention of any input involving secondary care staff or patients. Previous studies have illustrated that asthmatic patients attending accident and emergency departments in inner city areas are a notoriously difficult target for asthma care and are often poor at attending for follow up. ${ }^{3}$ No mention is made of how many of those seen in general practice as part of the intervention were repeated attenders at accident and emergency departments, or vice versa.

What this study does illustrate are the difficulties encountered in providing health care within inner city areas, where staff can become demoralised and face tremendous difficulties in targeting care effectively. It poses more questions than it answers and highlights the need for rigorous protocols in such studies, which need to target specific, easily measured outcomes.

Helen Parnell clinical nurse specialist STHHPGMCGP@aol.com

NT Cooke consultant chest physician

Airways Clinic, St Helier Hospital, Carshalton, Surrey SM5 1AA

1 Premaratne UN, Sterne JAC, Marks GB, Webb JR, Azim $\mathrm{H}$, Burney PGJ. Clustered randomised trial of an $\mathrm{H}$, Burney PGj. Clastered randonised tial of an intervention to inprove the inanagement of asthma: June.)

2 Burr L. Social deprivation and asthma. Respir Med 1997;91:603-8.

3 Garrett JE, Mulder J, Wong-Toi H. Characteristics of asthmatics using an urban accident and emergency department. N Z Med J 1988:101:359-61.

\section{Psychotherapy for severe personality disorder}

\section{Evolution is part of the therapeutic} process of therapeutic communities

EDITOR-Kisely bases his ideas of what comprises a therapeutic community on a mode that has undergone considerable evolution and development over 50 years. ${ }^{1}$ The Henderson Hospital and its offshoots are based on a specific type of therapeutic community, which started the social psychiatry movement after the second world war. Although it still provides a robust and effective treatment, several other types of therapeutic community are now used in the treatment of severe personality disorder.

Perhaps the most radical departure is to run the programmes as day services, as occurs in Reading. Francis Dixon Lodge in Leicester does not use small group therapy, and the Cassell Hospital is unusual in incorporating individual psychotherapy in the programme. Research is clearly needed, but the methodological difficulties are formidable. The treatment is complex and volatile and is delivered in very different ways; patient drop out is often part of the clinical process, long term follow up is essential, and measuring robust and useful personality change is difficult.

Randomised controlled trials are being considered, for day units as well as the new Henderson units, but they will not answer the question "Is a different type of therapeutic community better than this one?" or "What is going on here that is important?" As each therapeutic community differs con- siderably from every other, findings from randomised controlled trials will be difficult to generalise. And as evolution in response to the administrative environment is part of the therapeutic process of these communities, they could not be considered therapeutic communities if they were exactly defined and not allowed to change.

A project funded by the National Lottery and covering 10 centres is under way to isolate the "active ingredients" across a range of therapeutic communities for severe personality disorder. It is being coordinated by the Association of Therapeutic Communities and should help to define meaningful outcomes and identify relevant processes. The methodology is path analytic structural equation modelling. This is much more complex than a randomised controlled trial and, in the hierarchy of acceptable evidence, is not far below it. The protocol is available at www.pettarchiv.org.uk/atcprotocol.htm .

In his commentary on the article Pelosi writes in a belittling way of people with personality disorder. They have nearly always suffered extreme disturbance of emotional development (usually neglect, trauma, abuse, or loss in early life) and find it difficult to establish and sustain a normal life. To describe deeply disturbed people in the way that he does is surely unprofessional.

Rex Haigh consultant psychotherapist West Berkshire Psychotherapy Service, Reading RG1 7YL rexhaigh@therapeuticcommunities.org

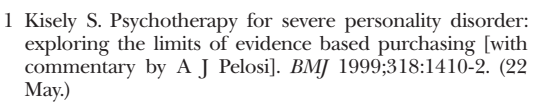

1 Kisely S. Psychotherapy for severe personality disorder: exploring the limits of evidence based purchasing [with commentary by A J Pelosi]. BMJ 1999;318:1410-2. (22 May.)

\section{Article did not do justice to available research data}

EDITOR-Psychotherapy for severe personality disorder has certainly been neglected. Unfortunately, Kisely's article does not do justice to available research data and consequently comes to unwarranted conclusions about commissioning. ${ }^{1}$

In contrasting the outcome of research in therapeutic communities (inpatient) with dialectical behaviour therapy (outpatient) Kisely does not compare like with like. There are no adequate data on which to compare studies, and there are none on patients randomly assigned to treatment in therapeutic communities, in day hospitals, and as outpatients. Criticism is made of the Patuxent study on reoffending rates, but this is a blunt outcome measure with complex determinants which may not be appropriate in terms of health economics or psychosocial variables.

Kisely states that the best evidence is for commissioning dialectical behaviour therapy, but such therapy was not in fact a recommendation in the strategic review. ${ }^{2}$ Compared with his comments about therapeutic communities, his criticisms of the unreplicated studies are curiously muted. All subjects were female. Men may be harder to treat. He fails to mention that there were no 
differences on some measures and that differences disappeared at follow up. New findings from Seattle suggest that if treatment with selective serotonin reuptake inhibitors is considered, some of the early differences between groups disappear $(\mathrm{H}$ Heard, personal communication).

We have conducted a randomised trial of 38 patients with borderline personality disorder who were treated with a psychoanalytically informed intervention. ${ }^{3}$ The results show that treatment in a specialist setting is superior to treatment as usual. We doubt, however, that this will (or should) lead to a call for commissioning of psychoanalytically informed treatments. Commissioning decisions must not depend solely on unreplicated studies of a small number of patients simply because they are randomised trials.

We performed a systematic review of the effectiveness of psychotherapeutic treatment of personality disorders, taking into account case identification, comorbidity, randomisation, specificity and context of treatment, and meaningful outcome measurement. ${ }^{4} \mathrm{We}$ concluded that the evidence neither suggests superiority of one therapy over another nor indicates which subgroup of patients should be offered psychotherapy as inpatients, day patients, or outpatients. Moderately effective treatments tend to be well structured, devote effort to enhancing compliance, have a clear focus, be theoretically coherent to both therapist and patient, be long term, encourage a powerful attachment relationship, and be well integrated with other services. Both treatment in a therapeutic community and dialectical behaviour therapy meet these criteria.

Effective commissioning for personality disorder remains difficult. The real problem lies in an unbiased assessment of the literature, identifying adequate funding for further research, and developing appropriate protocols measuring meaningful outcome.

Anthony W Bateman consultant psychiatrist in psychotherapy

St Ann's Hospital, London N15 3TH

anthony@mullins.demon.co.uk

Peter Fonagy professor

Psychoanalysis Unit, University College London, London WC1E 6BT

1 Kisely S. Psychotherapy for severe personality disorder: exploring the limits of evidence based purchasing [with
commentary by A J Pelosi]. BMJ 1999;318:1410-2. (22 comr

2 NHS Executive. NHS psychotherapy services in England: review of strategic policy. London: Department of Health, 1996

3 Bateman AW, Fonagy P. The effectiveness of partial hospitalisation in the treatment of borderline personality disorder-a randomised controlled trial. Am J Psychiatry (in press).

4 Bateman AW, Fonagy P. Effectiveness of psychotherapeutic treatment of personality disorder. BrJ Psychiatry (in press)

Randomised controlled trials may not be best for studies of clinical situations

EDITOR-Kisely acknowledges the limits of evidence based medicine but presents an analysis that exemplifies the difficulties that can arise when this model is used without reference to its limitations.
The author examines two studies of the outcome of treatment in a therapeutic community, in 235 and 137 patients, and compares them unfavourably with a trial of dialectical behaviour therapy in 39 patients. If it were not for the unavailability of this therapy in the United Kingdom he would like to draw purchasing lessons from this comparison. The most substantial reason for this conclusion is that the smaller study had a randomised controlled design whereas the larger studies had an observational design. It must also be noted that the effectiveness of dialectical behaviour therapy was studied in a sample confined to women aged 18-45 who had borderline personality disorder and were suicidal. Such patients constitute a small subset of all those with severe personality disorder.

The comparison shows some consequences of the rigid application of evidence based medicine's hierarchy of evidence, which grades studies according to design excellence and places randomised controlled trials at the head of the list. ${ }^{2}$ This approach favours certain interventions, notably brief treatments (which minimise dropout) and novel approaches (as otherwise control subjects can go elsewhere to obtain a desirable treatment to which they have not been randomised). In particular too, a randomised controlled trial requires that patient variation be minimised in order that before and after comparisons are not too obscured by initial variation within treatment groups.

For these reasons, while the randomised controlled trial is rightly the gold standard for trial design, it has some essential inadequacies as the sole design for studies of clinical situations, a point that has been well made before. ${ }^{3}$ Alternative trial designs can yield valuable information and should be considered on their merits-something we think Kisely failed to do.

Researchers in psychotherapy are aware of these problems, and well designed studies are becoming available. They need, however, to be interpreted and compared with reference to the context of the interventions under scrutiny. Models and standards are useful but should be handled with care.

S Pearce specialist registrar

Psychological Therapies Service, Royal South Hants Hospital, Southampton SO14 0YG Spjustp@iop.kcl.ac.uk

C Dare reader

Psychotherapy Section, Institute of Psychiatry, London SE5 8AZ

1 Kisely S. Psychotherapy for severe personality disorder: exploring the limits of evidence based purchasing [with commentary by A J Pelosi]. BMJ 1999;318:1410-2. (22 May.)

2 Geddes JR, Harrison PJ. Closing the gap between research and practice. Br J Psychiatry 1997;171:220-5.

3 Black N. Why we need observational studies to evaluate the

effectiveness of health care. BMJ 1996;312:1215-8.

\section{Author should have got the facts right}

EDITOR-I wish to correct just one of the factual errors in Kisely's article on the limits of evidence based purchasing of psychotherapy for severe personality disorder-an error repeated in Pelosi's commentary on the article. ${ }^{1}$ The author states (twice) that the NHS Executive's strategic review of psychotherapy services in England recommended dialectical behaviour therapy for the treatment of personality disorder. ${ }^{2}$

As the lead author of the review report, I can assure readers that it did not. What we did say was that at that time (1996) the strongest evidence from randomised controlled trials of efficacy in treating borderline personality disorder was for dialectical behaviour therapy, and for treating avoidant personality disorder the strongest evidence was for social skills training in combination with cognitive techniques. The report also pointed out that the paucity of controlled treatment trials weakens recommendations, that this is a field in which rapid progress is to be expected over the next few years, and that there will be a lag between new clinical developments and results of trials.

The review emphasised that it is not desirable to purchase only a limited range of treatment packages, targeted at certain diagnostic groups, that meet a hypothetical efficacy criterion. This is because there is no good effectiveness evidence, one way or the other, for many clinical practices. When appropriate controlled treatment research has not yet been undertaken, the absence of evidence of efficacy is not evidence of ineffectiveness. This hardly adds up to a recommendation that dialectical behaviour therapy is the only treatment of choice for personality disorder.

Glenys Parry professor associate

University of Sheffield School of Health and

Related Research, Sheffield S1 4DA

g.d.parry@sheffield.ac.uk

1 Kisely S. Psychotherapy for severe personality disorder: exploring the limits of evidence based purchasing [with commentary by A J Pelosi]. BMJ 1999;318:1410-2. (22 Mav.)

2 NHS Executive. NHS psychotherapy services in England: review of strategic policy. London: Department of Health,

\section{Author's reply}

EDITOR-These correspondents seem to have missed the purpose of my article. This was to explore the limits of evidence based purchasing, not to recommend one particular form of psychotherapy over another. The comparison of Henderson-type therapeutic communities with dialectical behavioural therapy was to illustrate the existence of other models for the treatment of severe personality disorders. Others include cognitive analytical therapy and the approaches of the Cassell Hospital or Francis Dixon Lodge.

The article clearly highlighted how none of the interventions for severe personality disorders was entirely satisfactory. No one has disagreed with the methodological issues I raised about the evaluation of the Henderson-type model or the lack of research evidence to provide central funds for further units. I also discussed several of the weaknesses of dialectical behavioural therapy, such as small study numbers and the relative lack of expertise in the United Kingdom. Bateman and Fonagy have added a few more. 
The authors of two letters have criticised my article on the basis of anticipated research findings (Haigh) or publications in press (Bateman and Fonagy), making a response difficult. Bateman and Fonagy state that their forthcoming review takes into account case identification, comorbidity, randomisation, specificity of treatment, context of treatment, and meaningful outcome measurement. In that case, have they included the research from the Henderson Hospital in their review? If they have, how have they dealt with the methodological flaws I have highlighted? If they have not, what is the relevance to the issue of central funding for Henderson-type units?

Parry is right to say that the NHS strategic review highlighted how the paucity of controlled treatment trials weakened the recommendations it could make for the treatment of personality disorder. The fact remains that the review concluded that the strongest evidence for efficacy was for dialectical behavioural therapy, and that this was at variance from the Reed report, which favoured therapeutic communities. ${ }^{1}$ Indeed, therapeutic communities are not mentioned at all in the one paragraph that the strategic review devotes to the efficacy and effectiveness of psychotherapies for personality disorder (paragraph 4.2.5.9). ${ }^{2}$

Everyone agrees that more research is needed and that a wide range of treatment packages should be purchased. Why then has only the Henderson-type model received central funding? It is more appropriate to acknowledge openly the limits of evidence based medicine than to rely on flawed studies that give the illusion that evidence exists. Let us be honest about how, when, and if we use research evidence.

Stephen Kisely senior lecturer in psychiatr

Primary Care Mental Health Unit, University of

Western Australia, Fremantle, WA 6160, Australia

Stephenk@cyllene.uwa.edu.au

1 Department of Health and Home Office. Report of the Department of Health and Home Office working group on psychopathic disorder. London: HMSO, 1994

2 NHS Executive. NHS psychotherapy services in England: review of strategic policy. London: Department of Health, 1996.

\section{Are postal prompts really ineffective?}

EDITOR-Given the evidence presented in the POST study, a well designed cluster randomised trial, we were a little surprised that the investigators concluded that postal prompts to general practitioners have a "marginal role" in improving the secondary prevention of coronary heart disease.

The authors found that recording and advice were significantly increased for all except one of the measures of risk factor, dramatically so for some measures (such as recorded cholesterol measurement). Also, for their principal prescribing outcome measures ( $\beta$ blockers and cholesterol lowering drugs), the odds ratio was nonsignificantly raised to $1.7-$ which, if real, seems clinically important. The failure to detect a statistically significant difference may reflect the absence of a real effect or simply a type 2 error due to insufficient power.

We agree that the overall level of prescribing of $\beta$ blockers and cholesterol lowering drugs in both arms of the study was disappointing. The finding that postal prompts were effective in influencing a range of process measures shows that rather than dismissing the intervention as ineffective we should be exploring further the reasons for the more modest effect on prescribing. The challenge then is to devise interventions or introduce policies that deal with the barriers to the implementation of evidence based practice.

For example, anecdotal evidence from discussions with general practitioners in Northumberland suggests that the failure to prescribe statins for cholesterol lowering is rarely lack of knowledge of best practice. Rather, general practitioners express concerns about the cost implications of long term prescribing of relatively expensive drugs to a large proportion of their practice population. If such systematic barriers exist then no amount of prompting, postal or otherwise, is likely to bring about the adoption of best practice.

Richard Edwards lecturer in public health medicine Department of Epidemiology and Public Health, University of Newcastle upon Tyne, Newcastle upon Tyne NE2 4HH

P.R.Edwards@ncl.ac.uk

Paul Murphy primary care information manager Northumberland Health Authority, Morpeth

\section{Feder G, Griffiths C, Eldridge S, Spence M. Effect of postal prompts to patients and general practitioners on the qual- ity of primary care after a coronary event (POST) thy of primary care after a coronary event (POST);
randomised controlled trial. BMJ 1999;318:1522-6. (5 June.)}

\section{Factors that might have eased principals' entry into practice}

EDITOR-I agree with the points made by Cave $^{1}$ in response to Easterbrooke's personal view. ${ }^{2}$ It is important to recognise, however, that most new principals have an unstructured and often traumatic entry into their first principal's post. I recently asked a group of young principals, all within their early years in practice, to identify factors that might have eased their entry into practice.

Seven main areas were identified.

Induction-All agreed that every new partner should have a period of induction similar to that provided for new general practitioner registrars.

Nominated doctor-All wished that they had a clearly identified partner in the practice to whom they could relate in their early years in practice. This would not be a mentor but someone who would clarify organisational matters and give feedback on performance as they settled into practice.

Protected time-In the early months in practice new partners should have time protected from clinical work in which to develop understanding about the systems and organisation of the practice, as well as just to think and reflect on their work.

Appraisal-Although many partnerships have a mutual assessment at six months, no true feedback was given at the end of this period. New principals would appreciate a discussion about their strengths and weaknesses at this stage. They recognised that the skills to give this feedback may not be developed in all partnerships, and they wondered whether an independent person might be needed to facilitate such discussion.

Equality-All thought that they were treated as an equal in terms of work and involvement once they began in practice, but they recognised that they still had much to learn. They were unclear about how this was to be achieved, but all thought that they should be recognised as not being the equal of an established, experienced principal.

Practice style-All thought that information about workload, consulting speeds, and style of working of partners was needed.

Leaving after six months-The group was clearly anxious about leaving a practice after the six month assessment and how this was to be handled.

All of these areas seem reasonable and easily achievable. Why don't most practices comply?

George Taylor deputy director

Department of General Practice, University of Newcastle upon Tyne, Newcastle upon Tyne NE1 7RU

G.B.Taylor@newcastle.ac.uk

1 Cave J. All new GPs have problems when they first start in practice. $B M J$ 1999;318:1569. (5 June.)

2 Easterbrooke J. The emperor has no clothes on. BMJ 1999;318:173.(13 February.)

\section{Effectiveness of planned short hospital stays for mental health care}

\section{Older studies' definitions of lengths of stay are now outdated}

EDITOR-Johnstone and Zolese report their systematic review of the effectiveness of planned short hospital stays for mental health care. ${ }^{1}$ Their findings may leave casual readers believing that new evidence has been marshalled to show that brief admissions to a psychiatric hospital "do not encourage a 'revolving door' pattern of care for people with serious mental illness and may be more effective than standard care." Such a conclusion would be erroneous and, in an era of aggressive cost containment, dangerous.

In fact, this article merely presents a meta-analysis of four old and very different studies, each comparing "long" with "short" hospital stays. All the studies were performed more than 20 years ago, before the adoption of current diagnostic criteria (Diagnostic and Statistical Manual of Mental Disorders, fourth edition, and International Classification of Diseases, ninth revision) and modern treatment methods, such as use of selective serotonin reuptake inhibitors and atypical antipsychotic drugs. Further, the 
prominent decrease in psychiatric facilities (notably the American state hospital system) has meant that many of the patients with chronic mental illness who were institutionalised two decades ago are now subject to repeated acute care admissions to general hospitals. ${ }^{2}$

In the two studies by Glick et al that the authors cited, a short admission was defined as 21-28 days and a long admission as 90-120 days. Clearly, the adjectives short and long have since come to have very different meanings: a four week hospital stay today would generally be considered to be long. The other two studies were of a mixed sample of patients with either exclusively schizophrenic or "functional psychiatric" disorders that conceivably could encompass all personality, mood, and psychotic conditions. Can one draw an informed conclusion from pooling such outdated and heterogeneous data?

At best this meta-analysis presents a historical snapshot of distant relevance to today's world of inpatient psychiatry. Nevertheless, profit driven managed care companies may interpret this paper as justifying a solution to mental health cost control through the imposition of inappropriate limits on inpatient care.

Spencer Eth professor of psychiatry

Saint Vincents Hospital, New York, NY 10011, USA spenceth@pol.net

1 Johnstone P, Zolese G. Systematic review of the effectiveness of planned short hospital stays for mental health care. BMJ 1999;318:1387-90. (22 May.)

2 Talbott JA, ed Chronic mental patient Orlando: Grune and Stratton, 1984 .

3 Egger M, Smith GD, Phillips AN. Meta-analysis: principles and procedures. $B M J$ 1997;315:1533-7.

\section{Authors' reply}

EDITOR-Eth is right that only old trials that met inclusion criteria for our systematic review on short versus long stays were identified, but he is wrong when he says that our findings are of distant relevance to today's psychiatry. We started the review with an important question. Over the past 40 years, the lengths of patients' stays in hospital have been reduced so that mental institutions can be closed and to contain costs in many countries. As a result, there is serious public concern about the alternative-community care-after many deaths and repeated acute care admissions of seriously mentally ill patients, as Eth rightly identified. ${ }^{12}$ Some governments are now suggesting increasing hospital based care as part of their modernisation programmes. ${ }^{3}$ With all these policy changes, we simply asked: which is more effective from the patient's point of view, longer or shorter stays?

The question is important to today's mental health service, and so the low level of research is both a disappointment and a challenge. We also share the concern that policy is driven by little research evidence, whether made by managed care companies in the United States or by the NHS in the United Kingdom. Yet most resources are spent on wards, staff, and buildings. ${ }^{4}$ There have been important advances in the treatment of serious mental illnesses, so why is there no recent robust and pragmatic research on how hospital care is organised and delivered?

Paul Johnstone director of public health Tees Health Authority, Middlesbrough TS7 0NJ Paul.johnstone@email.tees-ha.northy.nhs.uk

Gabriella Zolese consultant psychiatrist Pathfinder Mental Health Services NHS Trust, London SW17 7DJ

1 Department of Health. Report of the inquiry into the care and treatment of Christopher Clunis. London: HMSO, 1994

2 Todd NA, Bennie EH, Carlisle JM. Some features of new long-stay male schizophrenics. $\mathrm{Br} \quad J \quad$ Psychiatr 1976;129:424-7

Department of Health. Government increases number of secure beds for mental health patients. London: DoH, 1999. (Press release 1999/0439.)

Knapp M, Beecham J. Costing mental health services. Psychol Med 1990;20:893-908.

\section{Moving beyond journals}

\section{Print journals perform important} functions

EdiTor-Too much attention has been given to the dissemination function of journals and its improvement through the application of electronic publishing methods. I see little, actually nothing, that refers to the other important functions performed by the current scheme of journal publication. Preservation of the scholarly record is one such function, and it is not addressed at all in the $B M$ /s proposal. ${ }^{1}$ Librarians are not forgetting it, though-and we must remind the academic community not to forget it either. No amount of handwaving or references to "advanced technology" which will solve this problem "somehow" alters the fact that there is no electronic equivalent to print on acid free paper. Electronic signatures decay; equipment becomes obsolete and disappears; companies merge or dissolve, and their promises of access "in perpetuity" may vanish too. Some serious discussion of this matter is necessary.

Concerns about the quality of materials posted to an electronic site are justified. Even now, with editing and review, authors are often lazy with their references ("Tokyo Meeting, 1964"), spell creatively, write impenetrably. Adherence to at least minimum standards of syntax, spelling, use of the scholarly apparatus, and some degree of comprehensibility in the text is enforced by the threat of refusal to publish unless the author complies. What would happen in the absence of these controls?

In the $B M / \mathrm{s}$ scheme, and in the E-Biomed proposal as well, there is no discussion of how the contributions would be indexed, if they are to be, and by whom. There is some talk about "powerful search engines." Well, if that's all searchers have to rely on, they should prepare themselves for some interesting, even hilarious, results.

The stakes are high. There are some things the received model of journal publication does very well. Prudence and caution are needed, as well as enthusiasm for the possibilities of the new publishing methods.
Alex Bienkowski reference librarian Moody Medical Library, University of Texas Medical Branch, Galveston, TX 77555-1035, USA abienkow@utmb.edu

1 Delamothe T, Smith R. Moving beyond journals: the future arrives with a crash. BMJ 1999;318:1637-9. (19 June)

\section{Physicists do it in large groups}

EDIToR-Since Delamothe and Smith refer to the physics eprint server (xxx.lanl.gov) at the Los Alamos National Laboratories, ${ }^{1}$ may I present a viewpoint from the physics trenches? As they say, this form of publication descended from the high energy physics community. Like the medical community, the physics community is varied. Traditionally, the high energy people worked in large groups of perhaps several hundred researchers, so their papers were extensively internally reviewed before submission, and they would routinely send out hundreds of preprints at submission time. At the other end of the spectrum are the tabletop physics folks, who work in ones and twos, who would send out a few preprints. It is interesting to follow the evolution of the use of the Los Alamos server. For some (psychiatric?) reason, physicists embraced electronic interactions from the very beginning, perhaps because we're used to talking to machines.

Published papers sometimes have a footnote: "We published a previous version on the Los Alamos server and oops, the previous version was wrong in parts." My impression is that the tabletop community also happily puts their papers on the server, but often only after the papers have been peer reviewed and accepted.

In case people count the number of hits to the Los Alamos server http://xxx.lanl.gov, they should be aware that $\mathrm{xxx}$ is a code here for s-x rated, and that xxx sites are the most visited of any. (I am indebted to Abby Goodrum of Information Science at Drexel for pointing this out to me. Previously, I had associated xxx only with beer barrels.)

As an experimentalist, I applaud that the $B M J$ is starting an experiment. I trust that the electronic access will be as user friendly and fast as the present $e B M J$ and will follow the "push-technology" by which an engine will automatically present articles of interest, say, at weekly intervals.

Most people will continue to give most attention to printed, refereed journals, in all fields. Despite many pronouncements, most people still do their serious reading using paper, and will continue to do so. ${ }^{23}$

Leonard Finegold Physicist

Drexel University, Philadelphia, PA 19104, USA

L@Drexel.edu

1 Delamothe T, Smith R. Moving bevond journals: the future arrives with a crash. $B M J$ 1999;318:1637-9. (19 June.) 2 Bad news for trees. Economist 1999.949(6 March):122-6. 3 Crawford W, Gorman M. Future libraries: dreams, madnes and reality. Chicago: American Library Association, 1995.

\section{Rapid responses} éBM]

Correspondence submitted electronically is available on our website www.bmj.com 